\title{
A comparative study of aging of the elastic fiber system of the diaphragm and the rectus abdominis muscles in rats
}

C.J. Rodrigues and A.J. Rodrigues Junior
Laboratório de Anatomia M édico-Cirúrgica, Departamento de Cirurgia,

Faculdade de Medicina, U niversidade de São Paulo, São Paulo, SP, Brasil

\section{Correspondence \\ C.J. Rodrigues \\ Disciplina de Topografia \\ Estrutural Humana, FM, USP \\ Av. Dr. Arnaldo, 455, Sala 1304 \\ 01246-903 São Paulo, SP \\ Brasil \\ Fax: + 55-11-852-4877 \\ E-mail: aldojunq@ mandic.com.br \\ Research supported by the Sandoz Foundation for Gerontological Research (047/89). Publication supported by FAPESP.}

Received November 18, 1999 Accepted August 22, 2000

\section{Abstract}

In the present study the age-related changes of the striated muscle elastic fiber system were investigated in the diaphragm and rectus abdominis muscles of 1-, 4-, 8- and 18-month-old rats. The activation patterns of these muscles differ in that the diaphragm is regularly mobilized tens of times every minute during the entire life of the animal whereas the rectus abdominis, although mobilized in respiration, is much less and more irregularly activated. The elastic fibers were stained by the Verhoeff technique for mature elastic fibers. Weigert stain was used to stain mature and elaunin elastic fibers, and Weigert-oxone to stain mature, elaunin and oxytalan elastic fibers. The density of mature and elaunin elastic fibers showed a progressive increase with age, whereas the amount of oxytalan elastic fibers decreased in both diaphragm and rectus abdominis muscles and their muscular fascias. These age-related quantitative and structural changes of the elastic fiber system may reduce the viscoelastic properties of the diaphragm and rectus abdominis muscles, which may compromise the transmission of tensile muscle strength to the tendons and may affect maximum total strength.

\section{Introduction}

Structural changes in the diaphragm due to the aging process, mainly in the muscle fibers, have been described (1-3) but few studies have assessed alterations of the interstitial connective tissue, which maintains muscle-tendon integrity and is involved in the transmission of muscular forces. During aging the extracellular matrix of the skeletal muscle undergoes remodeling to accommodate the growth of the muscle fibers (4). In a previous report we demonstrated a de- crease in the collagen concentration and muscle fiber size, accompanied by a rearrangement of the distribution of the types of muscle fibers in both diaphragm (DIA) and rectus abdominis (RA) muscles during aging (5).

It is known that the extracellular matrix of any part of the body is largely made up of elastic fibers (6). Little is known, however, regarding both the elastic fiber system of the skeletal muscles and the changes that occur as a function of aging and of the pattern of their functional mobilization (7). Hence, the 
present study was performed to evaluate the age-related changes of the elastic fiber system of two muscles that are activated differently, the diaphragm, which contracts regularly tens of times per minute and during the entire life of the animal, and the rectus abdominis, whose activation is much less frequent.

\section{Material and Methods}

Thirty-two male Wistar rats were used in this investigation. Groups of 8 animals were sacrificed $1,4,8$ or 18 months after birth and are referred to in this paper as young, young adult, adult and aged or older, respectively. Mean weights $( \pm$ SD) were $68 \pm 10.06,319 \pm$ $33.4,420 \pm 37.15$ and $458 \pm 43.34 \mathrm{~g}$, respectively. The animals received water and standard chow food ad libitum.

\section{Tissue isolation}

The animals were killed by ether inhalation. After death, a cross-section of the RA and of the entire right coastal DIA was obtained. One representative strip from both DIA and RA was fixed in a $10 \%$ formaldehyde solution, dehydrated, and embedded in paraffin. The paraffin blocks were sectioned, providing $5-\mu \mathrm{m}$ thick serial sections used for quantitative assessment of elastic fiber content.

\section{Staining procedure}

Three adjacent sections were submitted to one of the following selective methods for staining elastic fibers: Verhoeff's (V) iodine-iron hematoxylin method (8) to stain only the mature elastic fibers; Weigert's (W) resorcin-fuchsin method (9) to stain mature and elaunin elastic fibers, and Weigert's technique preceded by oxidation performed through oxone (WO), as previously described (10) to stain the oxytalan, elaunin and mature elastic fibers.

\section{Morphometric evaluation}

The linear density (LV) of the elastic fiber system was determined in 25 random microscopic fields per histologic section stained by the Verhoeff (LVV), Weigert (LVW) and Weigert-oxone (LVWO) techniques and all measurements were performed by the same observer. The sections were scanned randomly at $1,000 \mathrm{X}$ magnification in a continuous line from edge to edge, employing a test eyepiece reticule with 10 parallel lines and 100 points that contains a simple square lattice test system of 10,500 $\mu \mathrm{m}^{2}$. Each elastic fiber completely intersected by any one of the test lines was counted. The intersections of fibers with a test reticule are related to the length of those fibers per unit area, according to the equation $\mathrm{LV}=2 \mathrm{Na}$, where $\mathrm{Na}$ is the total length of fibers per unit area (11). The area of the tissue examined was determined by counting the number of points of intersection in tissue sample.

\section{Electron microscopy}

Small pieces of tissue were fixed in a solution containing $0.1 \%$ tannic acid and $3 \%$ buffered glutaraldehyde, followed by post-fixation in $1 \%$ osmium tetroxide for $1 \mathrm{~h}$. The fixed material was stained in $0.5 \%$ aqueous uranyl acetate overnight and routinely embedded. The sections were cut with an ultratome apparatus and doublestained with uranyl acetate and lead citrate. Thin sections $(70 \mathrm{~nm})$ were subsequently analyzed with a Zeiss 9S2 electron microscope.

\section{Statistical analysis}

The data on density of elastic fiber concentration in the tissue were analyzed by one-way analysis of variance (ANOVA) correlating them with age. $\mathrm{P} \leq 0.05$ was considered statistically significant. 


\section{Results}

Body weight and cross-sectional area of muscle fibers from both DIA and RA increased significantly as a function of age following a second degree curve, as previously reported (5). The usual three components of the elastic fiber system in the extracellular matrix were found in both muscles. In cross-sections, the elastic fibers of young rats were thin, straight and oriented perpendicularly to the long axis of the muscle cells (Figure 1). In the older animals, however, the elastic fibers were thickened and curled (Figure 2). These aging changes of the elastic fibers were easily demonstrated in 18month-old rat muscle.

At the ultrastructural level the mature
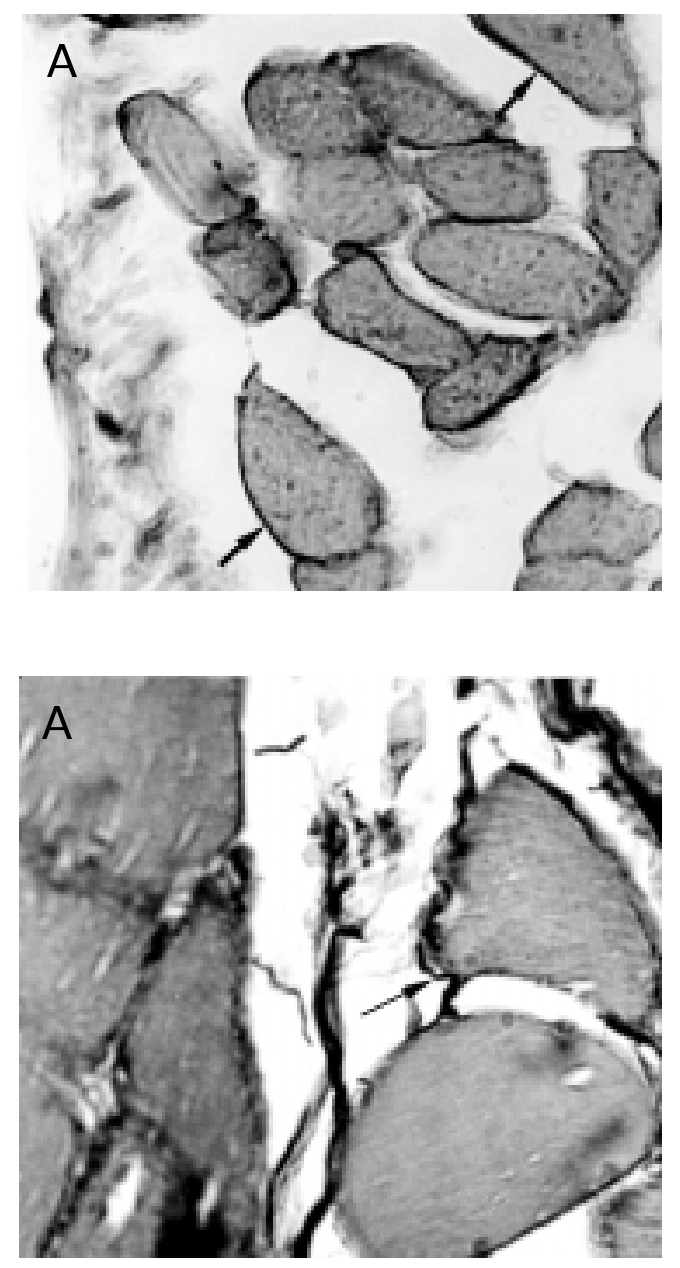

elastic fibers showed a central core of elastin surrounded by some microfibrils, while the oxytalan fibers were composed only of bundles of ordered microfibrils. The elaunin fibers exhibited a low amount of elastin (Figure 3). In the DIA and RA of aged rats we found foci of oxytalan fibers that were randomly distributed in an oval-shaped arrangement corresponding to abnormal oxytalan fibers (Figure 4).

The LV of elastic fibers in both muscles was quantified on selectively stained sections. $\mathrm{LV}$ values represented the total length of mature, elaunin and oxytalan fibers per unit area in WO-stained tissue, mature and elaunin fibers in W-stained tissue, and mature fibers in V-stained tissue. The mean values of LVV-, LVW- and LVWO-stained
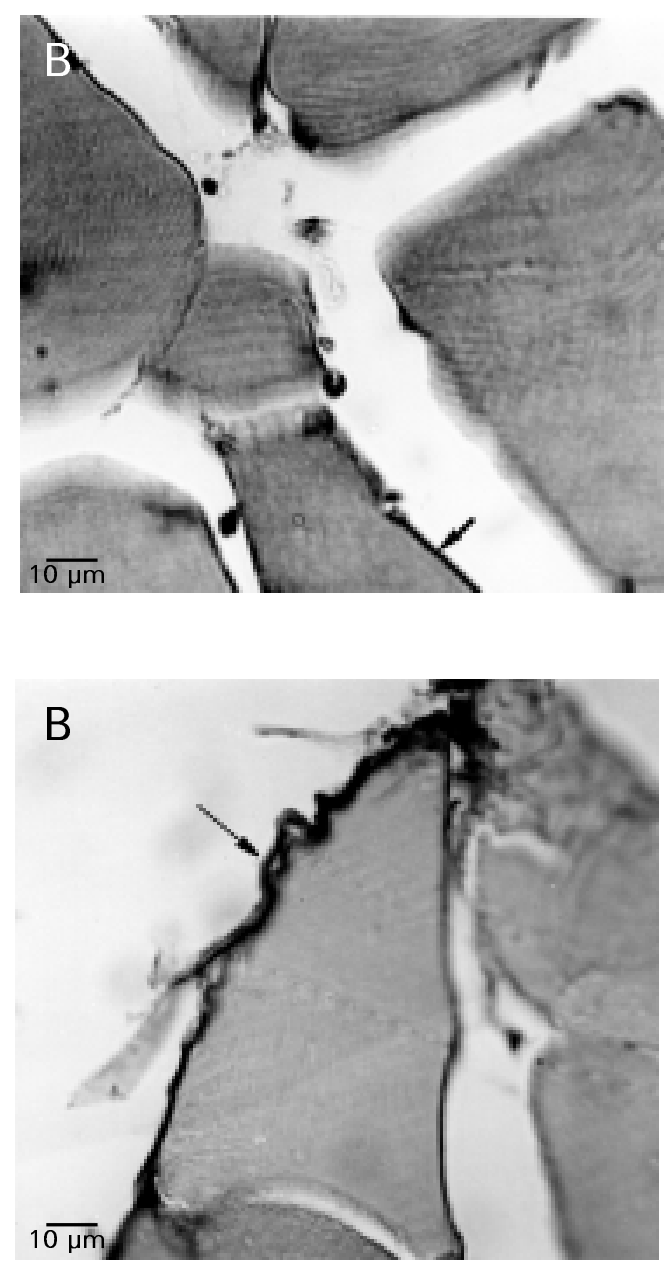

Figure 1 - Diaphragm (A) and rectus abdominis muscles (B) from a young (1 month) rat. Thin and straight elastic fibers (arrows) surrounding the muscle cells. Weigert-oxone stain (800X).
Figure 2 - Diaphragm (A) and rectus abdominis muscles (B) from an aged (18 months) rat. Thick and curled elastic fibers (arrows) surrounding the muscle cells. Weigert-oxone stain (800X). 
Figure 3 - Diaphragm muscle from an adult (8 months) rat. Elaunin elastic fibers (EL) run perpendicular to the long axis of the muscle cell $(28,500 X)$. fibers for each age group are indicated in Table 1 for the muscles, and in Table 2 for their muscular fascia. There was a positive correlation between LVV and LVW with age, and a negative correlation between age

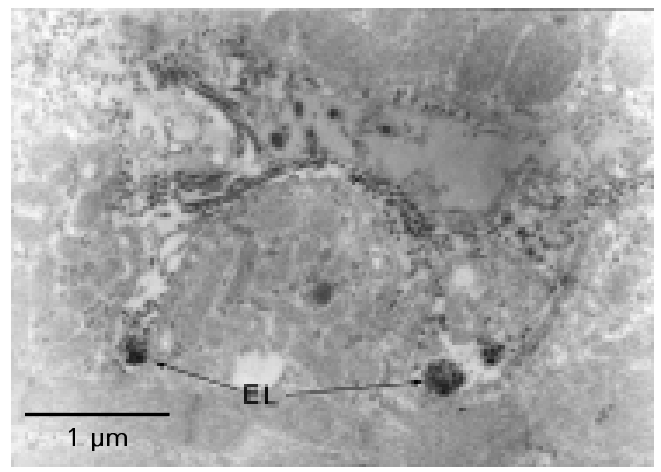

Figure 4 - Diaphragm muscle from an aged (18 months) rat. An abnormal oxytalan fiber (arrow) showing haphazardly arranged microfibrils $(28,500 \mathrm{X})$.

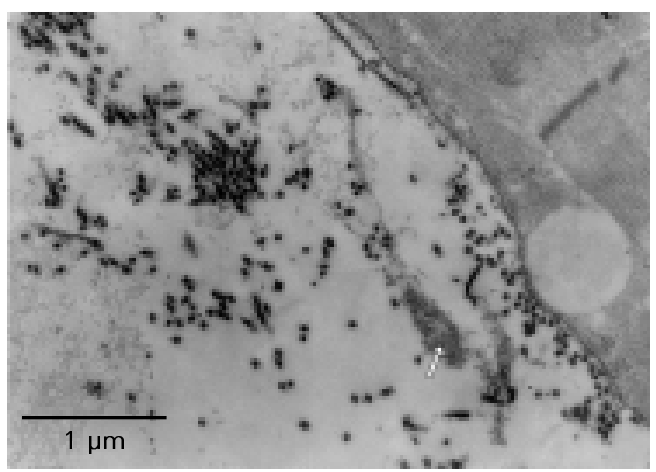

Table 1 - Linear density (LV) of the elastic fiber system.

Values are reported as the mean $\pm \mathrm{SD}\left(\times 10^{-3} \mu \mathrm{m}^{-2}\right)$; N, number of rats. WO, Weigertoxone; W, Weigert; $\mathrm{V}$, Verhoeff: methods for staining elastic fibers. The data on LV of elastic fiber concentration in the tissue were analyzed by ANOVA correlating them with age.

\begin{tabular}{lccc}
\hline Age (months) & LWWO & LWW & LW \\
\hline Diaphragm muscle & & & \\
$1(\mathrm{~N}=8)$ & $3.97 \pm 0.93$ & $0.92 \pm 0.22$ & $0.35 \pm 0.09$ \\
$4(\mathrm{~N}=8)$ & $2.59 \pm 0.64$ & $1.04 \pm 0.22$ & $0.53 \pm 0.12$ \\
$8(\mathrm{~N}=8)$ & $1.91 \pm 0.82$ & $1.17 \pm 0.26$ & $0.73 \pm 0.12$ \\
$18(\mathrm{~N}=8)$ & $1.47 \pm 0.38$ & $1.25 \pm 0.23$ & $0.82 \pm 0.19$ \\
& $\mathrm{~F}=18.28$ & $\mathrm{~F}=3.15$ & $\mathrm{~F}=19.79$ \\
& $\mathrm{P}<0.001$ & $\mathrm{P}<0.05$ & $\mathrm{P}<0.001$ \\
Rectus abdominis muscle & & & \\
$1(\mathrm{~N}=8)$ & $5.99 \pm 1.25$ & $1.71 \pm 0.19$ & $1.13 \pm 0.16$ \\
$4(\mathrm{~N}=7)$ & $3.86 \pm 0.82$ & $1.93 \pm 0.50$ & $1.35 \pm 0.62$ \\
$8(\mathrm{~N}=8)$ & $3.29 \pm 0.73$ & $2.38 \pm 0.72$ & $1.83 \pm 0.58$ \\
$18(\mathrm{~N}=7)$ & $2.78 \pm 0.49$ & $2.60 \pm 0.38$ & $1.90 \pm 0.65$ \\
& $\mathrm{~F}=17.02$ & $\mathrm{~F}=4.57$ & $\mathrm{~F}=3.48$ \\
& $\mathrm{P}<0.001$ & $\mathrm{P}<0.05$ & $\mathrm{P}<0.05$ \\
& & &
\end{tabular}

and LVWO in both DIA and RA and their muscular fascia.

\section{Discussion}

There was a progressive increase of the linear density of mature and elaunin elastic fibers and a decrease of the oxytalan fibers with age, as assessed in the DIA and RA muscles of the rat. Considering that the extracellular matrix of skeletal muscle has the function to maintain muscle-tendon integrity and the transmission of muscle tension, it is obvious that by altering the composition of collagen and elastin or changing their architectural arrangement, these properties may be compromised.

The tissue elasticity is primarily dependent upon the concentration of the mature and elaunin elastic fibers and the tissue resistance is related to the oxytalan elastic fibers (6). The high linear density of oxytalan fibers observed in both DIA and RA from young rats is a marker of a strong local mechanical stress (12). This result may be explained by the fact that in this phase of development the respiratory frequency is higher than in the adult, thus requiring a large overall mechanical work exerted by both the DIA and the RA, which is closely associated with respiration (13). If this hypothesis is correct, the abrupt decline in the quantity of oxytalanic fibers in both muscles in adult rats indicates a lower degree of mechanical load upon the DIA and RA. It is interesting that a reduction of oxytalan elastic fibers as a function of age was described for the pulmonary parenchyma of man with an abrupt decline between one and twenty years of age (11).

It is known that the concentration and the phenotypes of collagen may influence the muscular passive and/or active length-force and the viscoelastic properties (14). Furthermore, it has been demonstrated that slowtwitch muscles have a greater amount of collagen than fast muscles (15). In a previ- 
ous report we demonstrated a smaller amount of collagen in the RA muscle than in the DIA (5). In the present study we demonstrated a higher amount of elastic fibers in these rat RA muscles than in the DIA. These data were compatible with the function of RA muscle, which is faster and stronger.

With aging the DIA and RA muscles showed a smaller amount of oxytalan fibers, which promote resistance, and an increased amount of mature and elaunin fibers, which are the principal structural elements of elasticity $(6,10)$. However, these mature and elaunin elastic fibers undergo distortion of their normal architecture, becoming thicker, tortuous and fragmented. These morphological changes of the elastic fibers reduce their original elasticity because their total stretch is compromised and there are reduced breaks of hydrophobic links, with a consequent reduced storage of free and elastic energy (16). These structural alterations seem to be promoted by an increased and ordered arrangement of collagen (17), which compresses the elastic fibers, and by the action of tissue elastase, that causes degenerative changes in these fibers. Cannon and Read (18) showed evidence of increased elastolytic plasma activity in patients around 60 years of age with direct inguinal hernia when compared to the plasma activity of patients within the same age range but without hernias.

These age-related elastic fiber changes explain the skin looseness and wrinkling $(19,20)$, the weakness of the transversalis fascia, which promotes the high prevalence of direct inguinal hernia in the elderly (21), as well as the weakness of the fascia lata (22) and of the splenic capsule (23).
Table 2 - Linear density (LV) of the elastic fiber system.

Values of LV are reported as the mean \pm SD $\left(\times 10^{-3} \mu \mathrm{m}^{-2}\right) ; \mathrm{N}$, number of rats. For abbreviations, see legend to Table 1 . The data on LV of elastic fiber concentration in the tissue were analyzed by ANOVA correlating them with age.

\begin{tabular}{lccc}
\hline Age $($ months) & LVWO & LWW & LW \\
\hline Fascia of diaphragm muscle & & & \\
$1(\mathrm{~N}=8)$ & $23.76 \pm 4.01$ & $12.66 \pm 2.27$ & $5.25 \pm 0.82$ \\
$4(\mathrm{~N}=8)$ & $18.88 \pm 3.08$ & $13.93 \pm 1.27$ & $8.42 \pm 2.50$ \\
$8(\mathrm{~N}=8)$ & $15.89 \pm 1.81$ & $16.96 \pm 3.64$ & $9.17 \pm 2.82$ \\
$18(\mathrm{~N}=8)$ & $19.85 \pm 1.90$ & $21.06 \pm 1.86$ & $16.39 \pm 1.77$ \\
& $\mathrm{~F}=10.43$ & $\mathrm{~F}=18.24$ & $\mathrm{~F}=39.78$ \\
& $\mathrm{P}<0.001$ & $\mathrm{P}<0.001$ & $\mathrm{P}<0.001$ \\
Fascia of rectus abdominis muscle & & & \\
$1(\mathrm{~N}=8)$ & $20.24 \pm 3.66$ & $9.78 \pm 1.21$ & $6.19 \pm 1.15$ \\
$4(\mathrm{~N}=7)$ & $15.21 \pm 2.12$ & $11.86 \pm 1.74$ & $8.30 \pm 1.87$ \\
$8(\mathrm{~N}=8)$ & $12.92 \pm 1.90$ & $12.44 \pm 1.33$ & $9.54 \pm 1.38$ \\
$18(\mathrm{~N}=7)$ & $11.53 \pm 1.03$ & $12.64 \pm 1.18$ & $11.14 \pm 1.75$ \\
& $\mathrm{~F}=15.11$ & $\mathrm{~F}=6.01$ & $\mathrm{~F}=12.19$ \\
& $\mathrm{P}<0.001$ & $\mathrm{P}<0.01$ & $\mathrm{P}<0.001$
\end{tabular}

The decrease of oxytalanic fibers and the structural and architectural alterations in the elastic fibers that occur with aging in both DIA and RA would expose the interstitial collagen of skeletal muscle to deformation tensions higher than it normally endures. As a consequence, collagen fibers would be submitted to greater deformation, and since they represent a resistance element, they would end up by rupturing, promoting reduced muscle viscoelastic properties, which may compromise the transmission of tensile muscle strength to the tendons and may affect maximum total strength.

\section{Acknowledgments}

We thank Prof. Dr. Cesar Timo-Iaria for helpful comments. 


\section{References}

1. Daw CK, Starnes J W \& White TP (1988). Muscle atrophy and hypoplasia with aging: impact of training and food restriction. J ournal of Applied Physiology, 64: 2428-2432.

2. Eddinger TJ, Cassens RG \& Moss RL (1986). Mechanical and histochemical characterization of skeletal muscles from senescent rats. American J ournal of Physiology, 251: C421-C430.

3. Zhang $Y \&$ Kelsen SG (1990). Effects of aging on diaphragm contractile function in golden hamsters. American Review of Respiratory Disease, 142: 1396-1401.

4. Gosselin LE, Martinez DA, Vailas AC \& Sieck GC (1993). Interstitial space and collagen alterations of the developing rat diaphragm. J ournal of Applied Physiology, 74: 2450-2455.

5. Rodrigues $\mathrm{CJ}$, Rodrigues J unior AJ \& Bohm GM (1996). The effects of aging on the muscle fibers and collagen content of the diaphragm: A comparison with the rectus abdominis muscle. Gerontology, 42: 218-228.

6. Ross R (1973). The elastic fiber. A review. J ournal of Histochemistry and Cytochemistry, 21: 199-208.

7. Dieler R \& Schroder J M (1990). Increase of elastic fibers in muscle spindles of rats following single or repeated denervation with or without reinnervation. Virchows Archiv. A, Pathological Anatomy and Histopathology, 417: 213-221.

8. Verhoeff FH (1908). Some new staining methods of wide applicability including a rapid differential stain for elastic tissue. J ournal of the American Medical Association, 50: 876-877.

9. Weigert C (1898). Über eine Methode zur Färbung elastischer Fasem. Zentralblatt für Allgemeine Pathologie, und Pathologische Anatomie, 9: 289-292.

10. Fullmer HM \& Lillie RD (1958). The oxytalan fiber: a previously undescribed connective tissue fiber. J ournal of Histochemistry and Cytochemistry, 6: 425430.

11. Niewoehner DE \& Kleinerman J (1977). Morphometric study of elastic fibers in normal and emphysematous human lungs. American Review of Respiratory Disease, 115: 15-21.

12. Cleary EG \& Gibson MA (1983). Elastinassociated microfibrils and microfibrillar proteins. International Review of Connective Tissue Research, 10: 97-209.

13. Crosfilt M \& Widdicombe J (1961). Physical characteristics of the chest and lungs and the work of breathing in different mammalian species. J ournal of Physiology, 158: 1-14.

14. Mays PK, Bishop J E \& Laurent GJ (1988). Age-related changes in the proportion of types I and III collagen. Mechanisms of Ageing and Development, 45: 203-212.

15. Kovanen $V$, Suominen $H \&$ \&eikkinen $E$ (1984). Collagen of slow twitch and fast twitch muscle fibers in different types of rat skeletal muscle. European J ournal of
Applied Physiology, 52: 235-242.

16. Gosline J M (1978). Hydrophobic interaction and a model for the elasticity of elastin. Biopolymers, 17: 677-695.

17. Danielsen L \& Kobayashi T (1972). Degeneration of dermal elastic fibers in relation to age and light exposure. Preliminary report on electron microscopic studies. Acta Dermato-Venereologica, 52: 1-10.

18. Cannon DR \& Read RC (1981). Metastatic emphysema. Mechanism for acquiring inguinal herniation. Annals of Surgery, 194: 270-277.

19. Imayama S \& Braverman IM (1989). A hypothetical explanation for the aging of skin. American J ournal of Pathology, 134: 1019-1025.

20. Tsuji T \& Hamada T (1981). Age-related changes in human dermal elastic fibers. British J ournal of Dermatology, 105: 5763.

21. Rodrigues J unior AJ, Tolosa EMC \& Canvalho CAF (1990). Electron microscopic study on the elastic and elastic related fibers in the human fascia transversalis at different ages. Gegenbaurs Morphologisches J ahrbuch, 136: 645-652.

22. Bick EM (1961). Aging in the connective tissues of the human musculoskeletal system. Geriatrics, 16: 448-453.

23. Rodrigues CJ, Sacchetti J C \& Rodrigues J unior AJ (1999). Age-related changes in the elastic fiber network of the human splenic capsule. Lymphology, 32: 64-69. 